\title{
Creating a Clinical Systems Integration Strategy to Drive Improvement
}

\author{
Charles G. Macias, MD, $\mathrm{MPH}^{1, *}$ \\ Krystle A. Bartley, $M A^{1}$ \\ Travis L. Rodkey, $P h D^{2}$ \\ Heidi V. Russell, MD, PhD
}

\begin{abstract}
Address
*,1Department of Pediatrics, Center for Clinical Effectiveness, Baylor College of Medicine, Texas Children's Hospital, 6621 Fannin Street, Suite A2210, Houston, TX, 77030, USA

Email:cgmacias@texaschildrens.org

${ }^{2}$ Clinical Outcomes and Data Support, Department of Quality and Patient Safety, Texas Children's Hospital, 1102 Bates Avenue, FC 1440, Houston, TX, 77030, USA ${ }^{3}$ Texas Children's Cancer and Hematology Center, Baylor College of Medicine, Texas Children's Hospital, 701 Fannin St, Suite 1410.10, Houston, TX, 77030, USA
\end{abstract}

Published online: 2 0ctober 2015

C) Springer International Publishing AG 2015

This article is part of the Topical Collection on Quality Improvement

Keywords Clinical systems integration - Data analytics - Enterprise data warehouse $\cdot$ Big data $\cdot$ Population health

\section{Opinion statement}

Health care as an industry has lagged behind other industries in leveraging its data for improvement. Nevertheless, exemplary health care organizations have demonstrated substantial improvements for their patients by integrating data across their clinical, operational, and financial systems. We believe that all providers can use their data to drive improvements within the systems in which they practice. Here we explain the strides that Texas Children's Hospital has taken to improve care through the power of data. The foundation of clinical systems integration is converting the plethora of data acquired during the daily operations of an entire enterprise into analytics for meaningful interpretations of disease spectrums across the enterprise. Texas Children's Hospital focused on three domains of this foundation: (1) science- and evidence-based practice, (2) quality improvement education and implementation, and (3) data analytics and predictive analytics. As a result, we have seen improvements in the care for populations of children-which will be described at length for asthma, appendicitis, and cross-cutting payment reform models. Clinical systems integration requires investments in technical resources (i.e., software and hardware), re-engineering workflows, and human capital. The investments must be matched with leadership that understands and participates in the transformation-along with a governance structure that can 
help prevent fragmentation and inefficiencies that can occur in complex systems. Finally, the system should also be nimble enough to respond to changing internal and external quality demands.

\title{
Introduction
}

Fragmented medical care, variation in care delivery, and exorbitant costs are all signs of a health care system that needs to change. The Institute for Healthcare Improvement suggests a framework for optimizing health system performance: (1) a better overall patient experience, (2) improving the health of a population, and (3) delivering care at a better value [1]. Technology offers a means for improvement if we can mobilize its full potential and the connection begins with data. Barriers to using health data include fragmented and proprietary data collection and policies that limit data sharing (e.g., Health Insurance Portability and Accountability Act of 1996). The American Recovery and Reinvestment Act of 2009 provided $\$ 20$ billion to stimulate the growth of electronic medical records (EMRs) [2-4]. Unfortunately, EMRs are linked to the site of care-and as such-that one patient could have numerous bits of their medical history scattered across several practitioners and hospitals. Billing and claims information collected by insurers can bridge some of these practice silos; however, medical claims information offers minimal clinical information [5]. Reliance on the EMR alone to improve outcomes of care is unlikely to provide the data intelligence commensurate with the heavy national investment in health information technology. In 2005, a Rand report forecasted that the USA could save $\$ 80$ billion dollars annually from the rapid adoption of health information technology (HIT), but such savings were never realized; instead, health care expenditures have continued to grow. The disappointing return from the HIT investment has been attributed to multiple factors, among them are poor interoperability of systems and a failure of providers and infrastructures to re-engineer their care [6]. Centers of excellence, such as the Department of Veterans Affairs and Kaiser Permanente, have integrated data across their systems to improve care for their patients. These sites are uniquely poised because they function as both the provider and payer. We believe that all providers can use their data to drive improvements in their practice and within the systems in which they practice. This article provides an overview of the foundations of an effective data strategy through clinical systems integration.

\section{Definitions}

\author{
Big data
}

Although those in the health care industry are very familiar with the use of data (i.e., information stored in a digital form), the burgeoning information available today has driven the concept of "big data." Big data has been defined as "large volumes of high velocity, complex, and variable data that requires advanced techniques and technologies to enable the capture, storage, distribution, management, and analysis of

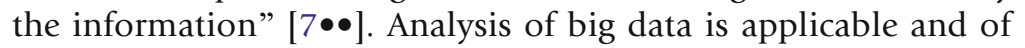
benefit to clinicians from single-physician offices to large hospital networks $[8 \bullet \bullet, 9]$. The right infrastructure and effective tools can transform any health care settings' data from an electronic repository, where data is in the hands of a few information technology (IT) data managers, to a tool that helps clinical providers predict the needs of their patients and guide decisions to deliver optimal care. 
Limitations of data management in health care are illustrated by the silos of data collection and storage in the typical IT structure. Data from a medical encounter may be stored in one repository, the financial information about that encounter in another repository, and staffing in yet another repository. Enterprise data warehouses have been developed, both homegrown and in concert with commercial vendors, to house large amounts of data from multiple sources in larger metadata banks that can handle the extensive volumes of data being generated rapidly.

In the world of informatics, data systems increase in sophistication from simple data gathering and reporting, as can be done from a patient EMR report at the bedside, to aggregating and analyzing data in populations or themes (data analytics), to predicting patients at risk (predictive analytics), or linking health observation with health knowledge to influence clinical decisions (prescriptive analytics or clinical decision support) [10•]. Incorporating clinical decision support capabilities into practice can improve workflow through ease of documentation, provide alert information at the point of care, and improve the cognitive understanding of the clinician [10•]. An institution or practice's hardware and software, and data management processes are critical to its capability of advancing along this continuum. Many EMRs are developing analytics platforms that embed some of these capabilities into their existing workflows; however, robust analytics must still overcome gaps in interoperability.

Clinical system integration (CSI)

Converting this plethora of data into meaningful interpretations through analytics is only the first step toward achieving the ultimate conversion of digital storage into knowledge that will drive improved outcomes. CSI provides a conceptual framework for a nimble yet deliberate process of translating data for synchronizing care delivery across silos of care. Simply stated, CSI facilitates the coordination of care across conditions, providers, settings, and time to achieve high-quality care [11]. It is more commonly evidenced in the literature emanating from accountable care organizations or universal payer systems where clinical integration should be easier to achieve, but have been applied within Texas Children's Hospital enterprise

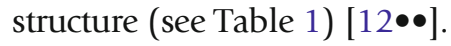

These characteristics require an amalgamation of evidence-based practice, measurement and analytics, and improvement-science-based implementation strategies with attention to clinical, operational, and financial factors. A system of evidence-based clinical standards must be present to create common understandings (shared baselines) of how care is to be delivered and to drive quality improvement that is as valid and reliable as current medical knowledge can provide. An implementation system is necessary to identify barriers to effective care delivery and improve systems 


\section{Table 1. Key principles for successful health systems integration}

\begin{tabular}{|c|c|c|}
\hline Domain & Definition & Example(s) \\
\hline $\begin{array}{l}\text { Comprehensive } \\
\text { services } \\
\text { across the } \\
\text { continuum }\end{array}$ & $\begin{array}{l}\text { Plan for and coordinate core services along the } \\
\text { continuum of care for the populations served } \\
\text { (e.g., from primary services to tertiary care and } \\
\text { from medical services to social services) }\end{array}$ & $\begin{array}{l}\text { Overarching coordination of care for children with } \\
\text { chronic complex diseases that includes inpatient } \\
\text { illnesses, preventive services, social support, } \\
\text { and education services }\end{array}$ \\
\hline Patient-centered & $\begin{array}{l}\text { Designing processes to improve patient/family } \\
\text { satisfaction and outcomes }\end{array}$ & $\begin{array}{l}\text { Include patient/family in health care design and } \\
\text { improvement. Encompassing all sources a } \\
\text { patient/family may seek out to improve their } \\
\text { health }\end{array}$ \\
\hline $\begin{array}{l}\text { Standardized } \\
\text { care delivery }\end{array}$ & $\begin{array}{l}\text { Interprofessional teams for all aspects of } \\
\text { designing and implementing care strategies } \\
\text { through shared baselines of care }\end{array}$ & $\begin{array}{l}\text { Evidence based guidelines, summaries, pathways } \\
\text { and protocols are developed and implemented } \\
\text { for medical condition to incorporate the input of } \\
\text { multiple types of professionals across a service } \\
\text { continuum. Workflows are facilitated through } \\
\text { decision support tools (including within the } \\
\text { EMR) }\end{array}$ \\
\hline $\begin{array}{l}\text { Performance } \\
\text { management }\end{array}$ & $\begin{array}{l}\text { Systems designed to monitor process and } \\
\text { outcomes to identify opportunities for further } \\
\text { improvement. These systems can be associated } \\
\text { with compensation }\end{array}$ & $\begin{array}{l}\text { Balanced scorecard reports that link clinical, } \\
\text { operation, and financial measurements for a } \\
\text { disease continuum, health care service, or } \\
\text { individual provider }\end{array}$ \\
\hline $\begin{array}{l}\text { Information } \\
\text { systems }\end{array}$ & $\begin{array}{l}\text { System wide computerized information systems for } \\
\text { data management, tracking of utilization and } \\
\text { outcomes, and enhancement of communication }\end{array}$ & $\begin{array}{l}\text { Using the EMR and EDW for population health } \\
\text { analytics to drive quality improvement efforts } \\
\text { with real-time or near-time dashboards and } \\
\text { decision support tools }\end{array}$ \\
\hline $\begin{array}{l}\text { Organizational } \\
\text { culture and } \\
\text { leadership }\end{array}$ & $\begin{array}{l}\text { Consistent leadership and engagement by } \\
\text { providers and administrators with a vision for } \\
\text { transforming care for better outcomes }\end{array}$ & $\begin{array}{l}\text { Governance structures that support clinical, } \\
\text { operational, and financial initiatives across an } \\
\text { organization }\end{array}$ \\
\hline $\begin{array}{l}\text { Physician } \\
\text { integration }\end{array}$ & $\begin{array}{l}\text { Including physician input and leadership into all } \\
\text { levels of the system }\end{array}$ & $\begin{array}{l}\text { Educating physicians in quality improvement } \\
\text { science. Recruiting physicians to participate in } \\
\text { the development, implementation and } \\
\text { evaluation of evidence based guidelines, } \\
\text { summaries, pathways and protocols }\end{array}$ \\
\hline $\begin{array}{l}\text { Governance } \\
\text { structure }\end{array}$ & $\begin{array}{l}\text { Bringing together organizations and services into } \\
\text { a coordinated, mutually supportive, integrated } \\
\text { system }\end{array}$ & $\begin{array}{l}\text { Representation by services across a health care } \\
\text { service to develop and oversee the application of } \\
\text { data from the EMR and EDW towards improving } \\
\text { outcomes }\end{array}$ \\
\hline $\begin{array}{l}\text { Financial } \\
\text { management }\end{array}$ & $\begin{array}{l}\text { Integration for better cost control and strategic } \\
\text { investment in outcomes that gain clinical value }\end{array}$ & $\begin{array}{l}\text { Integration of finance personnel at all levels of CSI } \\
\text { governance and within workgroups makes } \\
\text { cost-effectiveness of improvements integrated } \\
\text { and transparent }\end{array}$ \\
\hline
\end{tabular}

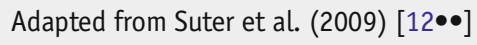

rapidly. A system of big data analytics is critical to aggregating data about subpopulations in near-time or real-time fashion to further inform quality improvement efforts. Measurement in such an integrated system should include clinical care outcomes but also measurement of the patient experience and the cost of care delivery - which are all critical to the Institute for Healthcare Improvement's Triple Aim [1, 11, 12••, 13]. 
Texas Children's Hospital's journey into transforming care delivery through the adoption of a clinical systems integration effort across its enterprise illustrates these concepts. Texas Children's Hospital is an enterprise that includes two children's hospitals, a women's hospital, an urgent care group, a network of over 50 primary care pediatric practices, multiple hospital quality associations, a health plan servicing over 300,000 lives, and physician service organizations. A robust data strategy was necessary for the clinical systems integration model to effectively transform large volumes of high-velocity data into meaningful knowledge. Thus, three domains were linked to this quality improvement effort, for which this article will focus on the domain of data management and analytics:

1. Science- and evidence-based practice. The Evidence Based Outcomes Center (EBOC) at Texas Children's Hospital was formed in 2007 initially to create order sets for the then upcoming EMR. The organization quickly realized the potential for driving high-quality clinical decisions through Clinical Physician Order Entry and engaged EBOC to create evidence-based guidelines and other clinical standards that could be embedded into the EMR. The tenet of quality improvement most important in this work centered on minimizing unwanted variation in practice for standardized care delivery; we could improve outcomes of care through reduction of waste (in diagnostic testing or therapeutic management, throughput, or error). The clinical standards produced by this team have been patient-centered, utilize the best evidence available or build consensus when evidence is lacking, and provide local context to national guidelines.

2. Quality improvement education and implementation. Texas Children's Hospital developed a number of tiered educational programs to assure that its workforce understands improvement science and could utilize the principles to improve the quality of care delivered by its health care infrastructure. The Advanced Quality Improvement course at Texas Children's Hospital, similar to programs described by Cincinnati Children's Hospital Medical Center and Intermountain Healthcare, has now trained over 175 clinicians and administrators [14]. Early learner curricula, online "just in time" training, and mentored medical trainee quality improvement projects provide additional opportunities for improvement education. In 2011, Texas Children's Hospital adopted a care process team implementation model with administrative and physician integration, which focuses on a subpopulation (typically diseasespecific) and is comprised of clinicians who are content experts, as well as experts in data analysis, EMR architecture, QI implementation, and evidence-based practice. The teams are charged with developing and implementing clinical standards across the care continuum for that disease process through rapid cycle improvement [15]. Each team and its efforts are 
permanently supported through shared resources and access to data gathering and advanced analytics.

3. Data analytics and predictive analytics. "Population health" is a relatively new and imprecise term, relating the health outcomes of a group of individuals to health determinants, policies, and interventions that affect those outcomes [16]. Including such information into clinical practice requires the assimilation and processing of data beyond that acquired within the EMR. Texas Children's Hospital created an Enterprise Data Warehouse (EDW) to encompass the EMR, financial information and staffing data, and other sources of data across its infrastructure. To analyze the data within the EDW, Texas Children's Hospital also developed subject area marts (a data platform around a specific disease or operational processes). This allowed for standardization of terminologies and measures across the enterprise, with visualization provided via near-time point-and-click dashboards, allowing for performance management. In aggregate, we could leverage our information systems to provide care process teams with the data they need to develop and assess interventions rapidly.

Through this clinical systems integration process of developing evidence-based practices, fostering the skills and mindset of quality improvement and implementation, and providing the tools for more complex analytics of our data, Texas Children's Hospital improvement efforts have expanded from one pilot care process team focused on acute asthma to teams tackling diabetes, bronchiolitis, pneumonia, bronchopulmonary dysplasia, spine surgery, appendicitis, hypospadias, tracheostomy, and pregnancy. More recent efforts include processes that cross diseases (e.g., septic shock) and the development of smaller teams aligned with clinical standards topics supported by data registries-rather than full care process teams. In order to be effective, the clinical systems integration efforts are empowered to address clinical, operational, and financial initiatives.

\section{Examples}

In 2011, a quantitative analysis was undertaken to determine potential targets for quality improvement through our clinical systems integration strategy. We had witnessed other health care systems perform impressive improvements in care using collaborative data and process improvement sharing across disease lines [17]. These collaborations improved value partly by providing some of the resources for data analysis and improvement science infrastructure that is not possible at a single practice. Since the inception of this initiative, there has been an increase in voluntary and mandated reporting of data meant, in part, to focus a practice's attention to areas of low quality and incentivize improvement in those priority areas. Despite the fact that such reporting can be cumbersome and resource intense, it can also provide value to the practice and the patients and is unlikely to go away [18]. Our CSI strategy has been adapting to develop 
systems, which makes reporting easier and more efficiently improve target areas.

Texas Children's Hospital identified clusters of disease processes within our system for which (1) care was costly, (2) there were large numbers of cases for the processes in question, and (3) when large variations in practice were noted. Once the target conditions were selected, care process teams were charged with the task of defining the patient population while parallel teams developed balanced scorecards of metrics that spoke to the highest quality of care for the area of focus. The patient populations and specific subcohorts were pulled and validated from the EDW through multiple identification strategies that included clinical decision rules, ICD-9/10 codes, anticipated problem lists, and medication lists. In parallel processes, a modified Delphi approach was employed to select quality measures for that disease process based on their importance, scientific acceptability, usability, and feasibility [19]. The care process teams then developed specific aims for rapid cycle process improvements utilizing internal data derived from the EDW in near-time fashion to drive each subsequent cycle.

1. Asthma was our first CSI initiative. National Asthma Education and Prevention Program guidelines were previously contextualized at TCH through EBOC, but outcomes remained subpar [20]. Shortly after the asthma subject area mart was assembled, data from our EDW revealed that nearly $60 \%$ of patients with an asthma exacerbation underwent a chest X-ray (CXR), an unnecessary procedure for most children (Fig. 1a). Furthermore, only $54 \%$ of patients with asthma received an Asthma Action Plan (AAP) upon discharge, which is a metric of quality asthma care according to the National Asthma Education and Prevention Program. The care process team began their improvement efforts by building clinical decision support into the EMR through an evidence-based order set. This guided providers toward a pre-determined course of action and decreased variation. The care process team also utilized venue-specific provider education and decision support in the EMR through rapid cycle process improvement. Run charts were generated from data within the EDW and emailed to physicians from the inpatient/observation units and emergency department on a weekly basis for monitoring of ongoing performance.

As of July 2015, CXR utilization remains below target-under $30 \%$ (Fig. 1a) and $97 \%$ of children receive an asthma action plan at discharge. We have observed increasing adherence to evidence-basedguidelines. The decrease in unwanted variation in practice and decrease in waste have allowed for a consistent decrease in length of stay from a baseline at 3.4 to 1.7 days. Furthermore, survey samplings of families of children with asthma have demonstrated greater confidence in selfmanagement and a better understanding of care delivery. The subsequent reduction in cost of care has driven our care delivery from an average loss of $\$ 2770.88$ per inpatient asthma visit (Fig. 1b), to an average margin contribution of $\$ 1020.18$ (Fig. 1c).

The care process team is currently working to improve adherence to beta agonist and oxygen weaning protocols, increasing influenza 


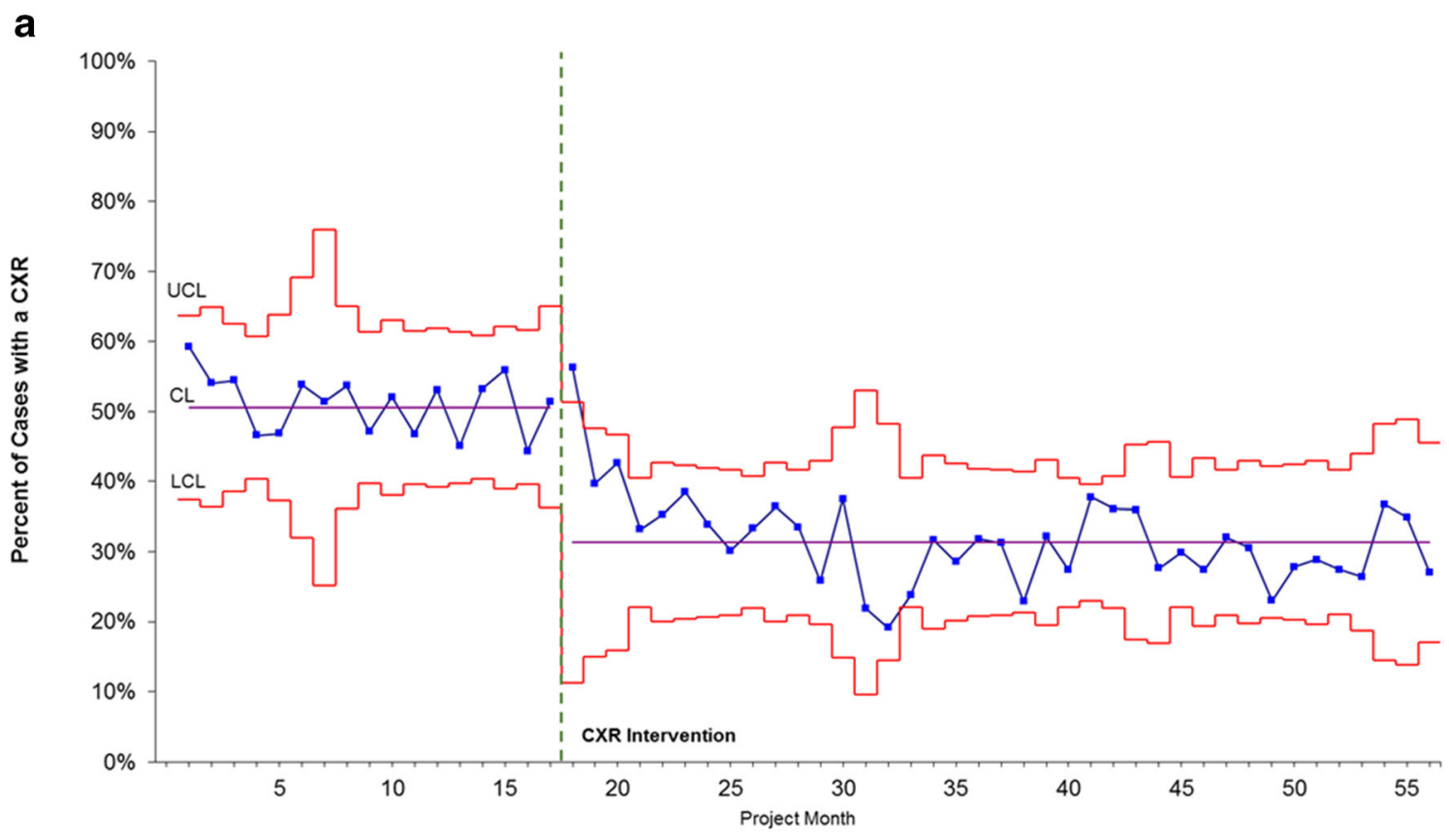

b

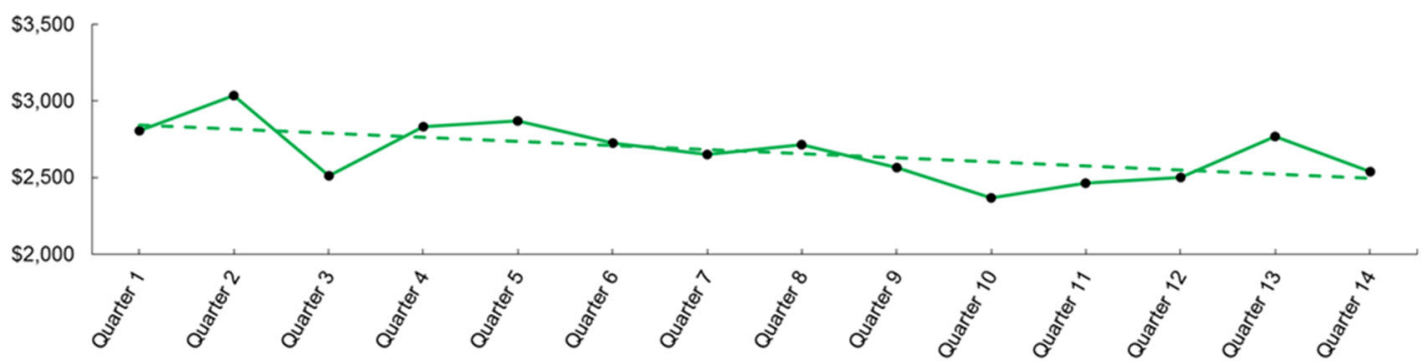

C

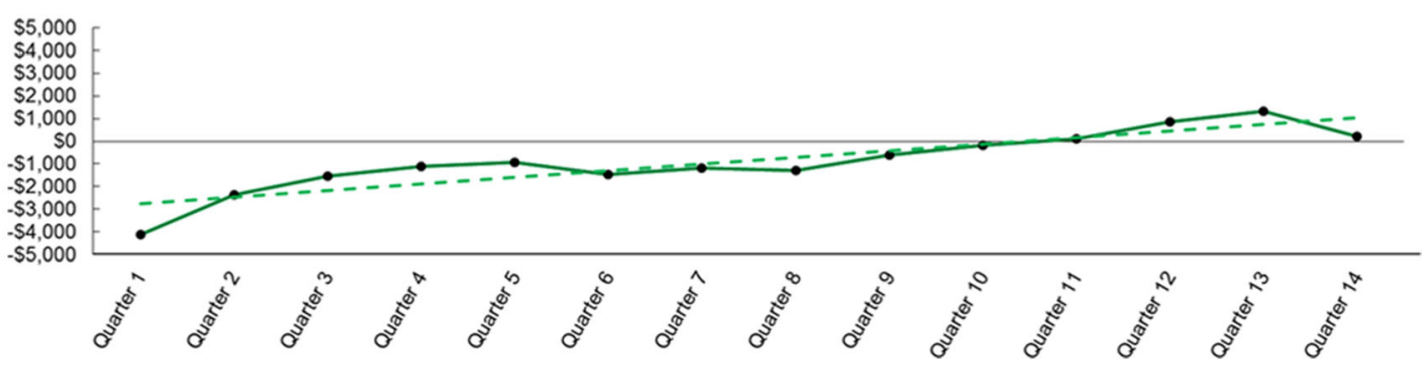

Fig. 1. a Percent of asthma patients receiving a chest X-ray. Statistical Process Control (SPC) P-chart illustrating the reduction in emergency center (EC), inpatient, and observation patients receiving chest radiographs before and after the Care Process Team (CPT) intervention (dashed line). Approximately $60 \%$ of patients received a chest radiograph in project month 1 , while approximately $28 \%$ of patients received a chest radiograph currently. The SPC chart was generated with the QIMacros package (KnowWare Intl, Inc.) for MS Excel. $U C L=$ upper control limit; $C L=$ control limit; $L C L=$ lower control limit. b Mean variable direct costs for asthma care. Average direct variable costs for acute asthma patients were computed and plotted for project quarters 1-14. All patients in the cohort included in this chart were clinical standards compliant. Linear regression analysis (dashed line) shows a decrease in cost over time (slope=negative) of $\sim 12 \%$ (\$345.30). c Margin contribution for asthma care. Financial margin contribution for acute asthma patients. Average margin contribution was computed and plotted over time. Linear regression (dashed line) shows an increase in margin contribution over time (slope=positive) from an average loss of $\$ 2770.88$ to a contribution of $\$ 1020.18$. 
vaccination, and implementing rapid steroid delivery. We have expanded the efforts of the asthma care process team to chronic asthma management in clinic-, home-, and school-based settings, improving the use of the Asthma Control Test ${ }^{\mathrm{TM}}$, rates of appropriate chronic steroid utilization, and appropriate follow-up visit scheduling. The combined acute and chronic efforts have incorporated over five specific aims at any given time and are improving outcomes of care across the entire population health continuum. With improvements in the patient experience, better outcomes for the population, and reduced cost of care, we are moving closer to achieving the triple aim for this subpopulation of children.

2. The first surgical condition that followed the aforementioned model was appendicitis. The appendectomy care process team worked with surgeons and nurses to map the workflow from diagnosis to post-operative care-which revealed areas of inefficiencies and opportunities for success. Variations in antibiotic ordering practices were managed with education and evidence-based order sets that were an impetus for improving appropriate monotherapy usage from 20 to $93 \%$. Risk stratifications were developed from our population to predict the risk of prolonged hospitalization. For simple appendicitis, the length of stay was reduced by $19 \%$ and cost of care reduced by $36 \%$ in a mixed cohort. In a clean cohort, the length of stay for simple appendicitis was reduced by 4.9 h (Fig. 2a) and cost of care was reduced by $5 \%$ in just 12 weeks (Fig. 2b). Our current focus of improvement is the phase of care from arrival to the health care setting to surgical resection. Reviewing existing data revealed patterns of delays, which are being addressed with scheduling and/or staffing modifications.

We currently have teams across the enterprise focusing on pediatric, pediatric surgical, and obstetrical processes. The data driving rapid cycle process improvement has evolved from simple data reporting to predictive analytics: the determination of at-risk children within a population based upon disease-specific cohort data analyzed from Texas Children's Hospital system but informed by risk factors described in the evidence. This has allowed us to build prediction models for subpopulations, including appendicitis, asthma, diabetes, and seizures.

3. While the need to improve outcomes aligns with vision and mission, the need to align with changing reimbursement paradigms is imperative for fiscal sustainability and growth. Our hospital, like many children's hospitals, cares for a particularly complex patient population. Since these patients are more likely to have public forms of medical insurance, changes in Medicaid reimbursement are significant external drivers of improvement [21]. In 2013, Texas Medicaid changed reimbursement from a per-diem scheme to prospective payment using patient-refined diagnosis related groups (APR-DRGs) [22]. APR-DRGs use an algorithm to classify clinically similar groups of patients who should have similar resource use. Focusing on cancer-related admission, which accounts for $11 \%$ of non-newborn hospital costs, Texas Children's Hospital used 
3 years of previous chemotherapy admissions to predict pharmaceuticals and activities most associated with exceeding APR-DRG reimbursement [23]. This allowed us to develop targeted improvements such as increasing outpatient services for drugs not being reimbursed in the hospital and rounding algorithms for drugs to decrease waste. These efforts illustrated an ability to utilize data to drive subgroups in population health models while remaining aligned and helping drive the financial management strategy.

Texas Children's Hospital integrated data analytics into its transformational health models with health care reform efforts in Texas creating burning platforms for children's hospitals to engage in value-based care delivery. These additional public payment reform initiatives included the institution
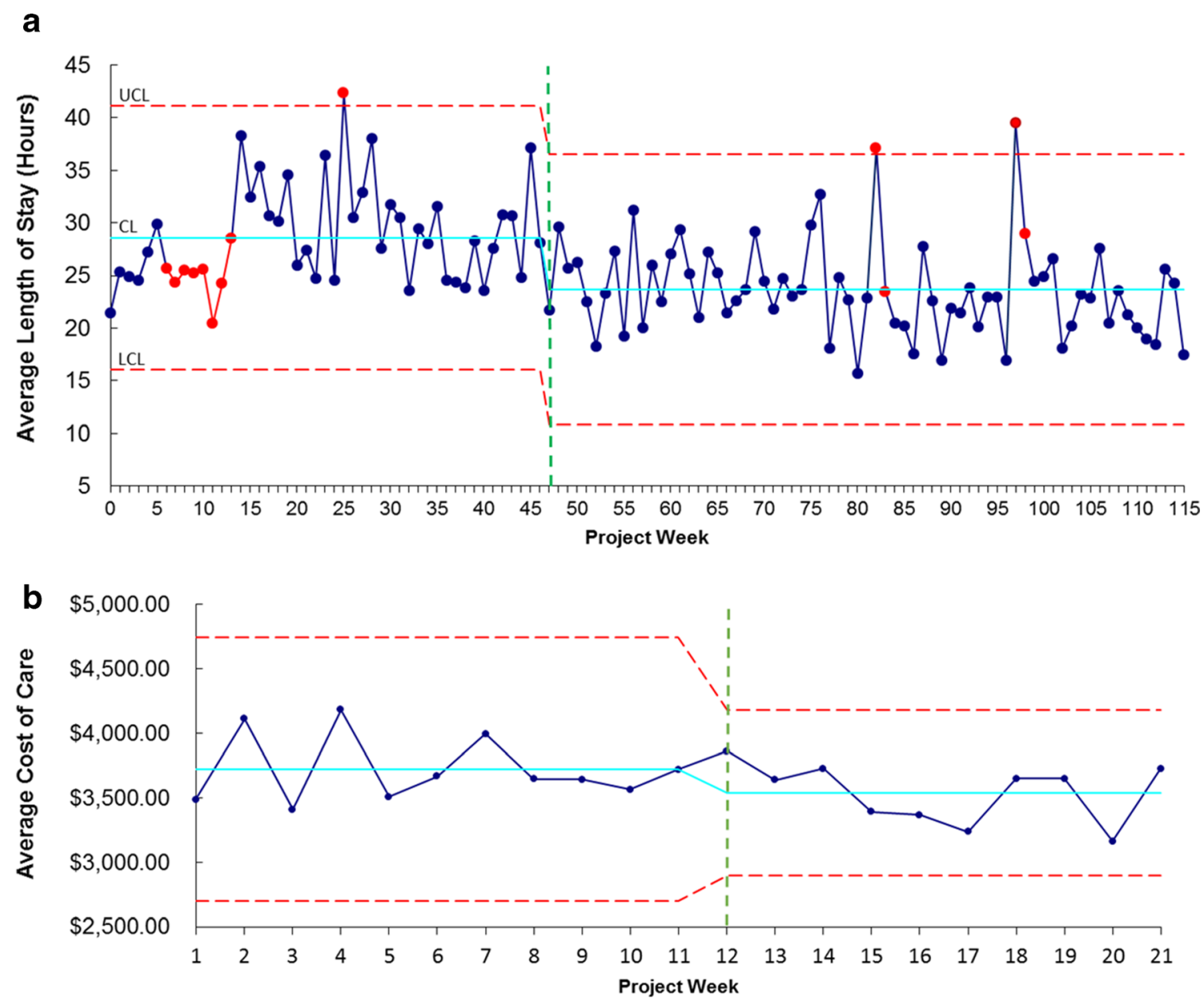

Fig. 2. a Length of stay for simple appendicitis. Reduction in length of stay (LOS) for simple appendicitis depicted by an SPC XMR (observation moving range) chart. Care Process Team intervention to reduce LOS occurred in project week 47 (dashed vertical line). LOS was reduced by an average of $4.9 \mathrm{~h}$ (17\%). Red dots signify special cause variation. b Cost of care for simple appendicitis. SPC XMR chart depicting reduction in the average direct variable cost of care for simple appendicitis patients. Care Process Team intervention to reduce cost of simple appendicitis care began in project week 12 (vertical dashed line). An approximately $5 \%$ reduction in cost of care $(\$ 180.19)$ was observed between the beginning and the end of the project. 


\section{Lesson learned}

of value-based strategies through the Delivery System Reform Incentive Payment 1115 Healthcare Transformation Waiver program. This program ties its fourth- and fifth-year payments to reporting and improving prespecified quality metrics. Similarly, penalties for health care systems with potentially preventable events above pre-set thresholds are currently in millions of dollars and require an institution to examine these quality metrics over their entire system. Texas Children's Hospital clinical systems integration approach, driven by data analytics, is integral to our ability to rise to the challenge when reimbursements are increasingly focused on value.

EMRs and other information systems are costly to implement and to maintain. Furthermore, beyond the hardware and software to collect the data is a requirement for human investment. Data within the most spectacular system is worthless if not interpreted and applied. Our experience suggests that optimal teams include experts in evidence-based medicine, data architects, and analysts, in addition to health care providers, and administrators. The size and level of expertise of such a team depend on the problem, but all domains are necessary. Additionally, re-engineering of the workflow is critical to maximize the investment of HIT, analytics, and decision support. This requires a cultural change driven by leadership - understanding and participating in the transformation of health care that analytics can drive.

When Texas Children's Hospital embarked on this care delivery transformation, data analytics and enterprise-wide data collection was novel in our system and was met with skepticism. Therefore, cautious investment was appropriate. Five years later, requests for support to build additional care process teams and access information from the enterprise data warehouse have far outstripped resources initially allocated. Staying apprised of internal and external quality demands requires a nimble system of both data collection and of human resources.

The use of data across multiple entities (health plan, hospital, clinics, and primary care physician offices) has created legal challenges to utilizing data for improvement purposes, and added delays to achieving the optimal integration of systems. Collaboration with legal counsel is critical to assuring that standards are in place to protect the privacy of data while allowing robust enough usage within the health care system, in analytics modeling, and integrated in a health information exchange. Shortfalls in our analytics strategy became evident as silos of clinical improvement efforts emerged, particularly around surgical, medical, and obstetrical processes from limited governance overseeing care process teams and analytics activities. Now under a new governance structure, the organization is able to implement best practices, pool analytics, standardize metrics, provide clinical decision support, and optimize the EMR and EDW across the organization and aligned with organizational goals and priorities. Moreover, it is a growing necessity to deliver data intelligence in order to demonstrate evidence of value driven care for emerging payment reform strategies that pay on outcomes and not processes. Data governance must be iterative to accommodate 


\section{Conclusions}

new evidence discovery, growing amounts of data, evolving personal technologies, and a shifting payment landscape.

It was our intent to demonstrate the enormous potential for data and analytics to drive improvements in outcomes for patients, providers, and administrators. The examples we have discussed are associated with a large complex medical system; nevertheless, the fundamental tenets apply across settings. Through clinical systems integration driven by data analytics, we have reduced waste, decreased costs, improved standardization of care delivery, improved outcomes, and thereby improved value.

\section{Acknowledgments}

The authors would like to acknowledge the efforts of Dr. Monica Lopez, Dr. Ruben Rodriguez, and Kathleen Carberry for their work on the appendectomy initiative, along with Dr. Robert Moore and Terri Brown for their work on the asthma initiative.

\section{Compliance with Ethics Guidelines}

\section{Conflict of Interest}

Charles G. Macias, Travis L. Rodkey, Krystle A. Bartley, and Heidi V. Russell declare that

they have no conflict of interest

Human and Animal Rights and Informed Consent

This article does not contain any studies with human or animal subjects performed by any of the authors.

\section{References and Recommended Reading}

Papers of particular interest, published recently, have been highlighted as:

- Of importance

- Of major importance

1. Berwick DM, Nolan TW, Whittington J. The triple aim: care, health, and cost. Health Aff. 2008;27:759-69.

2. 111th US Congress. American recovery and reinvestment act (2009). Public Law No. 111-5. Effective Date: 17 February 2009.

3. 111th US Congress. Patient protection and affordable care act (2010). Public Law No. 111-148. Effective Date: 21 March 2010.

4. Department of Health and Human Services, Centers for Medicare \& Medicaid Services. Medicare and medicaid programs; electronic health record incentive program; Final rule. Federal Register. 2010;75:44313-44588.

5. Wills MJ. Decisions through data: analytics in healthcare. J Healthc Manag. 2014;59:254-62.

6. Abelson R, Creswell J. In second look, few savings from digital health records. The New York Times. 2013. http://www.nytimes.com/2013/01/11/ business/electronic-records-systems-have-not-reducedhealth-costs-report-says.html?_r=0. Accessed 28 July 2015. 
7.• Institute for Health Technology Transformation. Transforming health care through big data strategies for leveraging big data in the health care industry. 2013. http://c4fd63cb482ce6861463bc6183f1c18e748a49b87a25911a0555.r93.cf2. rackcdn.com/iHT2_BigData_2013.pdf. Accessed 28 July 2015.

A comprehensive description of the role of big data in healthcare.

8.•• Raghupathi W, Raghupathi V. Big data analytics in healthcare: promise and potential. Health Inf Sci Syst. 2014;2(3):3.

A comprehensive review of the role and potential of health analytics.

9. Burghard C. Big data and analytics key to accountable care success. IDC Health Insights. 2012. http://www01.ibm.com/common/ssi/cgi-bin/ssialias?infotype= SA\&subtype $=$ WH\&htmlfid=IML14338USEN. Accessed 28 July 2015.

10. Richardson JE, Ash JS, Sittig DF, Bunce A, Carpenter J, Dykstra RH, et al. Multiple perspectives on the meaning of clinical decision support. AMIA Annu Symp Proc. 2010;2010:1427-31.

A description of the functions of clinical decision support.

11. Goldwater J, Yuhasz L. Considerations for clinical integration. Truven Health Analytics. 2011. http:// truvenhealth.com/portals/0/assets/HOSP_11363_ 0712_ClinicalIntegration_WP_Web.pdf. Accessed 28 July 2015.

12.• Suter E, Oelke N, Adair C, Armitage G. Ten key principles for successful health systems integration. Healthc Q. 2009;13:16-23.

Systematic review of evidence and a framework for key principles in successful systems integration in healthcare.

13. Kaegi L. AMA clinical quality improvement forum ties it all together: from guidelines to measurement to analysis and back to guidelines. Jt Comm J Qual Improv. 1999;25:95-106.
14. Kaminski GM, Schoettker PJ, Alessandrini EA, Luzader C, Kotagal U. A comprehensive model to build improvement capability in a pediatric academic medical center. Acad Pediatr. 2014;14:29-39.

15. Langley GL, Moen R, Nolan KM, Nolan TW, Norman $\mathrm{CL}$, Provost LP. The improvement guide: a practical approach to enhancing organizational performance. 2nd ed. Institute for Healthcare Improvement; 2009.

16. Kindig D, Stoddart G. What is population health? Am J Public Health. 2003;93:380-3.

17. Mostashari F, Tripathi M, Kendall M. A tale of two large community electronic health record extension projects. Health Aff. 2009;28:345-56.

18. Lannon CM, Peterson LE. Pediatric collaborative improvement networks: background and overview. Pediatrics. 2013;131 Suppl 4:S189-95.

19. National Quality Forum. Measure Evaluation Criteria. 2015. http://www.qualityforum.org/docs/measure evaluation_criteria.aspx. Accessed 28 July 2015.

20. National Asthma Education Program Expert Panel Report 3. Guidelines for the diagnosis and management of asthma. National Heart, Lung, and Blood Institute, National Institutes of Health. 2007. http://www.nhlbi. nih.gov/files/docs/guidelines/asthgdln.pdf. Accessed 28 July 2015.

21. Berry JG, Hall M, Hall DE, Kuo DZ, Cohen E, Agrawal $\mathrm{R}$, et al. Inpatient growth and resource use in 28 children's hospitals. JAMA Pediatr. 2013;167:170-7.

22. Texas Medicaid \& Healthcare Partnership. Inpatient reimbursement: prospective payment methodology. TMPPM 2011 Hospital Services Handbook http:// www.tmhp.com/HTMLmanuals/TMPPM/2011/ 2011TMPPM-29-081.html. Accessed 28 July 2015.

23. Price RA, Stranges E, Elixhauser A. Pediatric cancer hospitalizations, 2009: statistical brief \#132. In: Healthcare Cost and Utilization Project (HCUP) Statistical Briefs [Internet]. Rockville: Agency for Health Care Policy and Research; 2006 Feb-. Available from: http://www.ncbi.nlm.nih.gov/books/NBK98448/ 